\title{
ĐẶC ĐIỀM LÂM SÀNG VÀ KẾT QUẢ ĐIỀU TR! BỆNH NHÂN SUY TĨNH MẠCH NÔNG CHI DƯớI BẰNG PHƯỚNG PHÁP LASER NỘI MẠCH
}

Trần Đức Hùng*, Phạm Vũ Thu Hà*, Nguyễn Thanh Hải*, Vũ Minh Phúc*

\section{TÓM TÁ̀T}

Khảo sát đặc điểm lâm sàng, một số yếu tố nguy cơ ở bệnh nhân suy tĩnh mạch nông chi dưới và hiệu quả điều trị suy tĩnh mạch nông chi dưới bằng can thiệp nội mạch sử dụng đầu phát laser 1470 nm tại khoa Tim mạch, Bệnh viện Quân y 103 , từ tháng $7 / 2016$ đến tháng $12 / 2017$. Nghiên cứu 178 bệnh nhân với 228 chi tổn thương, tuổi trung bình $52,14 \pm 12,499$. Nữ giới $68,5 \% \mathrm{Nam}$ $31,5 \%$. Một số yếu tố nguy cơ hay gặp: thường xuyên đứng trong thời gian dài $97,5 \%$, Phụ nữ khi mang thai và sau khi sinh con $74,8 \%$, thừa cân béo phì $10,2 \%$. Triệu chứng lâm sàng của bệnh: đau tức nặng chân $89,1 \%$, dị cảm ở chi dưới $79,0 \%$, chuột rút $31,9 \%$, phù $34,5 \%$. Theo phân loại CEAP, $58.5 \%$ bệnh nhân ở giai đoạn C2, 26,9\% ở giai đoạn C3, 13,4\% ở giai đoạn C4. Theo dõi sau 1 tháng điều trị 98,3\% bệnh nhân không còn dòng chảy trong tĩnh mạch hiển trên siêu âm Doppler, 93,2\% số bệnh nhân có cải thiện rõ rệt triệu chứng. Biến chứng của kỹ thuật: bầm tím phần mềm vùng đùi $5,6 \%$, rối loạn cảm giác nông chi dưới $1,1 \%$. Thời gian trở lại sinh hoạt bình thường $1,06 \pm 0,3$ ngày, thời gian nằm điều trị 2,07 $\pm 0,42$ ngày.

Từ khóa: Suy tĩnh mạch, Laser nội mạch

\section{SUMMARY}

\section{CLINICAL CHARACTERISTICS AND RESULTS OF ENDOVENOUS LASER TREATMENT FOR VARICOSE VEINS}

To identify clinical characteristics, risk factors and evaluate safety, efficacy of endovenous laser treatment with the 1470-nm diode laser for patients with varicose veins in Cardiovascular department, 103 Military Hospital fromeJuly, 2016 to December, 2017. 178 consecutive patients (228 legs) with varicose vein. There were 122 women $(68.5 \%)$ and 56 men $(31.5 \%)$ with a mean of $52,14 \pm 12,499$ years. Risk factors: prolonged standing $(97,5 \%)$, pregnancy $(74,8)$, obesity $(10,2 \%)$. The chief clinical feature were heaviness on the legs $(89,1 \%)$, skin irritation $(79,0 \%)$, muscle cramps $(31,9 \%)$ and swelling $(34,5 \%)$. CEAP clinical categories were C2 (58.5\%), C3 $(26,9 \%)$ and $\mathrm{C} 4(13,4 \%)$. One month of follow-up: absence of flow on color Doppler imaging was noted in 98,3\%, clinical improvement 93,2\%. Major complications were swelling in the lower legs $(5,6 \%)$, paraesthesia $(1,1 \%)$. Time to return to normal activities was $1,06 \pm 0,3$ days and hospitalization time was $2,07 \pm 0,42$ days.

Keywords: Varicose veins, Endovenous laser treatment.

\section{I. ĐặT VẤN ĐỀ}

Suy tĩnh mạch nông chi dưới là bệnh lý có thể gặp ở mọi lứa tuổi, Tại Hoa Kỳ, có $23 \%$ người ở tuổi trưởng thành có tình trạng giãn tĩnh mạch nông và khoảng $6 \%$ có bệnh suy tĩnh mạch mạn tính, chi phí điều trị suy tĩnh mạch hàng năm tại Hoa Kỳ khoảng 150 triệu đến 1 tỷ USD [1]. Ở Việt Nam, theo tác giả Đinh Thị Thu Hương, $62 \%$ số bệnh nhân tại các phòng khám khi khám có biểu hiện của suy tĩnh mạch [3]. Phương pháp điều trị chủ yếu của bệnh trước đây là phẫu thuật thắt hoặc lấy bỏ tĩnh mạch bệnh lý. Tuy nhiên, phẫu thuật cũng đi kèm với một số biến chứng đáng kể sau khi phẫu thuật gồm chảy máu, nhiễm trùng, viêm tĩnh mạch và tổn thương thần kinh ở nông. Bên cạnh đó, phẫu thuật đòi hỏi gây mê và do đó tăng chi phí điều trị [2]. Nhưng năm gần đây, bệnh lý suy tĩnh mạch nông chi dưới được chú ý nhiều hơn do tính phổ biến cũng như sự

\footnotetext{
* Trung tâm Tim mạch, Bệnh viện Quân y 103 Ngườ chịu trách nhiệm khoa học: BS Trần Đức Hùng Ngày nhận bài: 01/05/2018 - Ngày Cho Phép Đăng: 20/05/2018 Phản Biện Khoa học: PGS.TS. Đặng Ngoc Hùng
} GS.TS. Lê Ngoc Thành 
phát triển của phương pháp điều trị bằng can thiệp nội mạch. Điều trị suy tĩnh mạch nông chi dưới bằng Laser hoặc sóng cao tần đang thay thế dần phẫu thuật tại các trung tâm can thiệp mạch. Tại khoa Tim mạch, Bệnh viện Quân y 103, Kỹ thuật can thiệp nội mạch điều trị suy tĩnh mạch nông chi dưới được tiến hành từ tháng 07/2016. Chúng tôi tiến hành nghiên cứu này với mục tiêu: Đánh giá đặc điểm lâm sàng, yếu tố nguy co ở bệnh nhân suy tĩnh mạch nông chi duới, kết quả điều trị can thiệp nội mạch bằng Laser điều trị bệnh nhân suy tĩnh mạch nông chi duới tại Bệnh viện Quân y 103.

\section{II. ĐỐI TƯợNG VÀ PHƯớng PHÁP NGHIÊN CÚ'U}

\section{1. Đối tượng nghiên cứu}

178 bệnh nhân được chẩn đoán suy tĩnh mạch nông chi dưới ở khoa Tim mạch, Bệnh viện Quân y 103 và điều trị suy tĩnh mạch nông chi dưới bằng laser nội mạch từ 07/2016 đến 12/2017

\subsection{Phương pháp nghiên cứu}

+ Thiết kế nghiên cứu: nghiên cứu mô tả

+ Tiêu chuẩn lựa chọn bệnh nhân: Bệnh nhân suy tĩnh mạch nông chi dưới có triệu chứng, phân độ từ $\mathrm{C} 2$, siêu âm có dòng trào ngược tại thân tĩnh mạch. Đáp ứng kém với điều trị nội khoa.

+ Tiêu chuẩn loại trừ: Bệnh nhân không có dòng trào ngược trong trong mạch hiển trên siêu âm doppler, bệnh nhân có huyết khối tĩnh mạch sâu kèm theo.

+ Nội dung nghiên cứu: Bệnh nhân được khám lâm sàng, siêu âm mạch chi dưới, đánh giá tổn thương theo phân loại CEAP:

\begin{tabular}{|l|l|}
\hline C0 & Chỉ có triệu chứng cơ năng \\
\hline C1 & $\begin{array}{l}\text { Giãn tĩnh mạch mạng nhện hoặc dạng lưới } \\
\text { đường kính }<3 \mathrm{~mm}\end{array}$ \\
\hline C2 & Giãn tĩnh mạch đường kính $>3 \mathrm{~mm}$ \\
\hline C3 & Phù, chưa có biến đổi trên da \\
\hline C4 & Biến đổi sắc tố da \\
\hline
\end{tabular}

\begin{tabular}{|l|l|}
\hline C5 & $\begin{array}{l}\text { Biến đổi sắc tố kèm loét do suy tĩnh mạch đã } \\
\text { liền sẹo }\end{array}$ \\
\hline C6 & Loét do suy tĩnh mạch đang tiến triển \\
\hline
\end{tabular}

Bệnh nhân được chỉ định điều trị can thiệp theo hướng dẫn của hội phẫu thuật mạch máu Hoa Kỳ [4]. Chúng tối sử dụng máy phát laser Venacure bước sóng $1470 \mathrm{~nm}$. Sau can thiệp bệnh nhân được đánh giá lại các triệu chứng, siêu âm tĩnh mạch chi dưới, đánh giá mức độ cải thiện chất lượng cuộc sống của bệnh nhân.

\section{KẾT QUẢ VÀ BÀN LUẬN}

\section{1. Đặc điểm về tuổi và giới tính}

\begin{tabular}{|l|l|l|}
\hline Đặc điểm & \multicolumn{2}{|l|}{ Kết quả $(\mathrm{n}=178)$} \\
\hline Tuổi & $52,14 \pm 12,49$ \\
\hline \multirow{2}{*}{ Giới tính } & Nam $(56)$ & $31,5 \%$ \\
\cline { 2 - 3 } & Nữ $(122)$ & $68,5 \%$ \\
\hline BMI & $22,67 \pm 2,66$ \\
\hline
\end{tabular}

Trong nghiên cứu của chúng tôi, tuổi trung bình là 52.14 , tuổi cao nhất là 78 , tháp nhất là 31 . Độ tuổi trung bình trong nghiên cứu của chúng tôi tương đương với nghiên cứu của Nguyễn Văn Trang và cộng sự [3]

Nữ giới có tỷ lệ suy tĩnh mạch chi dưới cao hơn nam giới do đặc điểm của nội tiết tố nữ, thói quen sinh hoạt và những thay dổi trong quá trình mang thai, sinh con. Trong nghiên cứu của Đặng Thị Minh Thu Nữ/Nam là 4/1 [6]. Trong nghiên cứu của chúng tôi tỷ lệ Nữ/Nam là 2.1/1.

\subsection{Một số yếu tố nguy co'}

\begin{tabular}{|l|c|c|}
\hline Yếu tố nguy cơ & Số bệnh nhân & Tỷ lệ \% \\
\hline Đứng lâu, ngồi lâu & 173 & $97,5 \%$ \\
\hline Sau sinh & 91 & $74,8 \%$ \\
\hline Thừa cân & 18 & $10,2 \%$ \\
\hline
\end{tabular}

Có $97,5 \%$ số bệnh nhân liên quan đến tình trạng thường xuyên đứng lâu, ngồi lâu, 74,8\% số bệnh nhân xuất hiện các suy tĩnh mạch sau khi sinh nở, $10,2 \%$ số bệnh nhân có thừa cân. Đây là 
các yêu tố nguy cơ liên quan đến suy tĩnh mạch nông chi dưới mạn tính [4] [6].

\section{3. Đặc điểm lâm sàng}

\begin{tabular}{|l|c|c|}
\hline Triệu chứng & Số bệnh nhân & Tỷ lệ \% \\
\hline Đau tức, nặng chân & 106 & $89,1 \%$ \\
\hline Tê bì, dị cảm & 94 & $79 \%$ \\
\hline Chuột rút & 38 & $31,9 \%$ \\
\hline Phù & 41 & $34,5 \%$ \\
\hline Chàm hóa & 17 & $14,3 \%$ \\
\hline $\begin{array}{l}\text { Giãn tĩnh mạch } \\
\text { dưới da }\end{array}$ & 34 & $28,6 \%$ \\
\hline Loét & 1 & $0,8 \%$ \\
\hline
\end{tabular}

Triệu chứng cơ năng thường gặp nhất là cảm giác đau tức, nặng chân chiếm $89,1 \%$ số bệnh nhân đến khám. Cảm giác tê bì $79 \%$, chuột rút về đêm $31,9 \%$ và phù là $34.5 \%$. Các triệu chứng ít gặp hơn là chàm hóa $14,3 \%$ và loét $0,8 \%$.

Phân loại CEAP:

\begin{tabular}{|c|c|c|}
\hline Phân loại & Số bệnh nhân & Tỷ lệ \% \\
\hline C2 & 70 & $58,8 \%$ \\
\hline C3 & 32 & $26,9 \%$ \\
\hline C4 & 16 & $13,4 \%$ \\
\hline C5 & 1 & $0,8 \%$ \\
\hline C6 & 0 & $0 \%$ \\
\hline
\end{tabular}

Phân loại CEAP cho thấy đa số bệnh nhân đến khám ở giai đoạn $\mathrm{C} 258,5 \%$ và C3 26.9\%. Kết quả nghiên cứu của chúng tôi phù hợp với một số nghiên cứu của tác giả trong nước, tỷ lệ bệnh nhân đến khám cao nhất ở giai đoạn C2, C3 [3] [4].

\section{4. Đặc điểm tổn thương}

\begin{tabular}{|l|l|c|c|}
\hline $\begin{array}{l}\text { Đặc điểm tổn } \\
\text { thương }\end{array}$ & Tỷ lệ & $\begin{array}{c}\text { Tổng } \\
\text { số }\end{array}$ \\
\hline \multirow{2}{*}{$\begin{array}{l}\text { Số lượng chi } \\
\text { tổn thương }\end{array}$} & $\begin{array}{l}\text { Tổn thương } \\
\text { một bên }\end{array}$ & $\begin{array}{c}99 \\
(55,5 \%)\end{array}$ & \multirow{2}{*}{228 chi } \\
\cline { 2 - 3 } & $\begin{array}{l}\text { Tổn thương } \\
\text { hai bên }\end{array}$ & $\begin{array}{c}79 \\
(44,5 \%)\end{array}$ & \\
\hline
\end{tabular}

\begin{tabular}{|l|c|c|}
\hline $\begin{array}{l}\text { Đường kính } \\
\text { tĩnh mạch } \\
\text { bệnh lý }(\mathrm{mm})\end{array}$ & TM hiển lớn & $7,02 \pm 2,45$ \\
\cline { 2 - 3 } & TM hiển nhỏ & $5,27 \pm 1,7$ \\
\hline $\begin{array}{l}\text { Thời gian } \\
\text { trào ngược } \\
\text { trên siêu âm } \\
\text { (giây) }\end{array}$ & TM hiển lớn & $3,12 \pm 1,09$ \\
\cline { 2 - 3 } & TM hiển nhỏ & $2,3 \pm 0,55$ \\
\hline
\end{tabular}

\subsection{Kết quả điều trị can thiệp}

Triệu chứng cơ năng sau can thiệp 1 tháng:

\begin{tabular}{|l|c|c|}
\hline Triệu chứng & Số bệnh nhân & Tỷ lệ \% \\
\hline Đau tức, nặng chân & 9 & $5.2 \%$ \\
\hline Tê bì, dị cảm & 3 & $1,6 \%$ \\
\hline Chuột rút & 0 & 0 \\
\hline Phù & 0 & 0 \\
\hline
\end{tabular}

Có 93,2\% số bệnh nhân nhận thấy triệu chứng cơ năng cải thiện rõ rệt so với trước điều trị, không có bệnh nhân nào còn triệu chứng phù và chuột rút.

Siêu âm đánh giá kết quả triệt đốt tĩnh mạch bệnh lý sau 1 tháng

\begin{tabular}{|l|c|}
\hline Đặc điểm & Số chi (Tỷ lệ \%) \\
\hline $\begin{array}{l}\text { Còn dòng chảy trong } \\
\text { tĩnh mạch hiển }\end{array}$ & $4(1,7 \%)$ \\
\hline $\begin{array}{l}\text { Tắc hoàn toàn tĩnh } \\
\text { mạch hiển }\end{array}$ & $224(98,3 \%)$ \\
\hline $\begin{array}{l}\text { Thời gian trở lại sinh } \\
\text { hoạt bình thường }\end{array}$ & $1,06 \pm 0,3$ ngày \\
\hline $\begin{array}{l}\text { Thời gian xuất viện } \\
\text { sau thủ thuật }\end{array}$ & $2,07 \pm 0,42$ ngày \\
\hline
\end{tabular}

Tiêu chuẩn đánh giá thủ thuật không thành công khi còn dòng trào ngược trong tĩnh mạch đã được điều trị can thiệp [2]. Trong nghiên cứu của chúng tôi, tỷ lệ thành công của thủ thuật 98,3\%. Theo Nguyễn Văn Trang tỷ lệ tắc hoàn toàn tĩnh mạch hiển sau can thiệp 98,1\% [3], theo L. H. Rasmussen là 99,3\% [2]. Thời gian phục hồi sau thủ thuật tương đương với các tác giả khác [2]. 


\subsection{Tai biến và biến chứng}

\begin{tabular}{|l|c|c|}
\hline \multicolumn{1}{|c|}{ Đặc điểm biến chứng } & $\begin{array}{c}\text { Số lượng } \\
\text { chi }\end{array}$ & Tỷ lệ \\
\hline Huyết khối tĩnh mạch sâu & 0 & $0 \%$ \\
\hline Nhiễm trùng tại chô̂ & 0 & $0 \%$ \\
\hline Rối loạn cảm giác & 3 & $1,1 \%$ \\
\hline Vết bầm tím sau điều trị & 13 & $5,6 \%$ \\
\hline Đau dọc tĩnh mạch & 12 & $5,04 \%$ \\
\hline
\end{tabular}

Trong nghiên cứu của chúng tôi không có biến chứng nặng như huyết khối tĩnh mạch sâu, nhiễm trùng tại chi thể điều trị, có $5,6 \%$ số bệnh nhân sau điều trị xuất hiện vết bầm tím sau điều trị và 5,04\% số bệnh nhân đau dọc tính mạch sau điều trị, các triệu chứng này đáp ứng tốt với điều trị nội khoa bằng thuốc giảm dau, chống viêm và thường hết sau 1 tuần. Có 3 chi sau can thiệp có tổn thương dây thần kinh lân cận gây rối loạn cảm giác nông. Tỷ lệ bầm tím theo Dietzek là $5,8 \%$ [8].

\section{KẾT LUẬN}

Qua nghiên cứu 119 bệnh nhân suy tĩnh mạch nông chi dưới được tiến hành can thiệp nội mạch điều trị tại khoa Tim mạch, Bệnh viện Quân y 103 từ tháng 7/2016 đến 12/2017, kết quả cho thấy: chủ yếu bệnh nhân là nữ giới, tuổi trung niên. Yếu tố nguy cơ liên quan tình trạng thường xuyên đứng lâu, ngồi lâu và phụ nữ sau sinh đẻ, biểu hiện của bệnh là cảm giác tức nặng chân, dị cảm, tê bì và siêu âm tĩnh mạch hiển giãn có dòng trào ngược. Phương pháp can thiệp nội mạch bằng Laser có tỷ lệ thành công cao, an toàn. Bệnh nhân sau thủ thuật có thể trở lại sinh hoạt bình thường ngay, thời gian nằm viện ngắn.

\section{TÀI LIỆU THAM KHẢO}

1. Jennifer Heller, MD (2011). Treatment of Chronic Venous Insufficiency. Supplement to endovascular today, October 2011, p12-13
2. L. H. Rasmussen, M. Lawaetz, L. Bjoern, B. Vennits, A. Blemings and B. Eklof (2011). British Journal of Surgery 2011; 98: 1088: 1079-1088

3. Nguyễn Văn Trang, Phạm Văn Phương (2015). Nghiên cứu ứng dụng điều trị suy tĩnh mạch nông chi dưới bằng đốt sóng cao tần tại bệnh viện đa khoa thành phố Cần Thơ

4. C. Wittens, A.H. Davies, N. Bækgaard, R. Broholm, A. Cavezzi, S. Chastanet,M. de Wolf, C. Eggen, A. Giannoukas, M. Gohel, S. Kakkos, J. Lawson, T. Noppeney, S. Onida, P. Pittaluga, S. Thomis, I. Toonder, M. Vuylsteke (2015). Eur J Vasc Endovasc Surg (2015) 49, 678-737.

5. M AVasquez and C E Munschauer (2008). Venous Clinical Severity Score and qualityof-life assessment tools: application to vein practice. Phlebology 2008;23:259-275.

6. Đặng Thị Minh Thu, Nguyễn Anh Vũ (2012). Đặc điểm lâm sàng và một số yếu tố nguy cơ của suy tĩnh mạch mạn tính chi dưới.

7. M. R. Cesarone, MD, G. Belcaro, MD, PhD, A. N. Nicolaides, MD, MS, G. Geroulakos, $\mathrm{MD}, \mathrm{PhD}, \mathrm{M}$. Griffin, PhD, L. Incandela, MD, M. T. De Sanctis, MD, M. Sabetai, MD, G. Geroulakos, MD, G. Agus, MD, P. Bavera, MD, E. Ippolito, MD, G. Leng, MD, A. Di Renzo, MD, M. Cazaubon, MD, S. Vasdekis, MD, D. Christopoulos, MD, PhD, and M. Veller, MD, Chieti, Italy and London, UK (2002). 'Real' Epidemiology of Varicose Veins and Chronic Venous Diseases: The San Valentino Vascular Screening Project. Angiology Volume 53, Number 2, 2002.

8. Alan M. Dietzek (2007). Endovenous Radiofrequency Ablation for the Treatment of Varicose Veins. Vascular, Vol. 15, No. 5, pp. 255-261. 